\title{
CLINICAL ASSESSMENT AND MICROLEAKAGE EVALUATION OF THREE ESTHETIC RESTORATIVE MATERIALS IN CLASS II IN PRIMARY MOLARS
}

\author{
Gihan M. Abuelniel*
}

\begin{abstract}
Aim : This study aimed to assess the clinical performance and to evaluate in-vitro microleakage in class II in mandibular second primary molars restored with three esthetic restorative materials.

Materials and Methods: In the clinical part of the study, sixty second mandibular molars indicated for class II preparation were divided into three equal groups. Molars were restored with three esthetic restorative materials according to manufacturer instructions as follows: group (1) Compomer (Dyract), group (2) Giomer (Beautifil) and group (3) Carbomer (GCP Glass Fill). Molars were evaluated clinically every 3 months for one year using modified USPHS Criteria. In the in-vitro part of the study thirty second mandibular molars were collected and divided in three equal groups. Molars were restored as in the clinical groups and sealed at root apices. Samples were subjected to thermocycling $\left(500\right.$ cycles, $\left.5^{\circ} \mathrm{C} / 55^{\circ} \mathrm{C}\right)$ and immersed in methylene blue dye for 24 hours at $37^{\circ} \mathrm{C}$. Specimens were sectioned mesio-distally and evaluated for microleakage by means of dye penetration scoring under stereomicroscope. Data were recorded and analyzed statistically.
\end{abstract}

Results:

- Compomer and Giomer groups showed statistically significant clinical success than the Carbomer group according to USPHS criteria.

- Microleakage at the gingival margin in all groups was statistically significantly than at the occlusal surfaces.

- Compomer and Giomer showed the least microleakage scores in Class II cavity preparations.

- $\quad$ Microleakage was statistically significant in Carbomer (GCP Glass Fill) group.

Conclusions: When esthetics and durability are of prime importance, compomer and Giomer serve as advocated esthetic restorative materials in class II in primary molars.

\footnotetext{
* Associate Professor of Pediatric Dentistry and Public Health Department, Faculty of Dentistry, Cairo University.
} 


\section{INTRODUCTION}

The main goal of restorative dentistry is certainly to restore teeth to their form and function. Seal and adaptation to cavity walls ensure the longevity of restorations. Endless efforts have been directed to enhance dental restorative materials adaptation and retention ability against ingress of oral fluids and microorganisms. ${ }^{[1]}$

For many years, amalgam was widely used restorative material for primary teeth. ${ }^{[2,3]}$ However, debates have been reported on potential hazardous effects of amalgam. In some countries, the use of amalgam in primary and permanent teeth was banned due to its mercury content. Recently, modifications in glass-ionomer cements and resin composites advocated their use as alternatives to amalgam. Their indications are not based mainly on their physical, chemical and mechanical properties, but also concerned with dental care needs of the child, such as degree of dental destruction, functional and esthetic sequelae caused by caries as well as the child's behavior. ${ }^{[4]}$

Scientific literature reveals a lack of randomized clinical follow-up studies of adhesive restorations in primary teeth. In a systematic review, which was used as inclusion criteria for randomized controlled trials with at least 6 months of clinical follow-up, only three studies could be included. According to the results, there is a lack of evidence to make any recommendations considering materials with better clinical performance for the primary dentition. ${ }^{[5]}$

A spectrum of tooth-colored restorative materials appeared in the dental market. Traditional glass ionomers (GICs) and resin composites represent the two ends, where newer products with intermediate properties vary in between. Traditional glass ionomers possess the advantage of fluoride release, minimal shrinkage, and resistance to microleakage. On the other hand, they show less esthetic and mechanical properties than composites. Resin modified glass ionomers (RMGI) and polyacrylic acid modified composite resins (compomers) are two materials with intermediate properties. Compomers are more closely related to composite resin, consisting of the same components as composite resin with the addition of glass ionomer. Fluoride release, good esthetics, better wear characteristics and shrinkage were among the advantages of compomers. ${ }^{[6]}$

Giomers are a new class of materials that have been introduced in response to the continuing need for improved glass ionomer like restorations. It has properties of both glass ionomers (fluoride release and recharge) and resin composites (excellent esthetics, good mechanical properties and biocompatibility). As giomer is a new material and only few studies have investigated its performance, further research was advocated. ${ }^{[7]}$

Recently, glass carbomer cement, a GIC based restorative material, has been introduced with claims of improved physical characteristics. This new material contains nano-sized powder particles and fluorapatite as secondary filler in a trial to improve its compressive strength and wear resistance. The reactive glass is treated with dialkyl siloxanes, where the addition of fluorapatite was justified by the in vivo chemical transformation of glass ionomer into a fluorapatite-like material in primary teeth. The liquid of glass carbomer is polyacrylic acid. Being a glass-ionomer based restorative, application of a surface protection may also help in the improvement of surface characteristics and sealing properties of the glass carbomer cement. In literature, lack of published data on the clinical use of glass carbomer cements was evident that suggested testing the material may provide valuable insights into its physical properties particularly in primary teeth. ${ }^{[8]}$

Microleakage around dental restorations is considered a major problem in clinical dentistry. It may be defined as 'the clinically undetectable passage of bacteria, fluids, molecules or ions between a cavity wall and the restorative materials applied to 
it'. This seepage contributes to hypersensitivity of restored teeth, teeth discoloration, recurrent caries, pulpal injury and accelerated deterioration of some restorative materials. Despite the development of various new materials like compomers, giomers and carbomers, very few materials actually bond to the tooth surface. Dimensional changes and lack of adaptation of the restoration to cavity walls can lead to bacterial ingress. Thus, the procurement of a perfect seal on the restoration tooth interface is one of the prime goals of restorative dentistry in order to ensure the longevity of restorations. ${ }^{[9]}$

\section{MATERIALS AND METHODS}

\section{The clinical part of the study}

This study was conducted at the Pediatric Dentistry Department, Cairo University. Parents or guardians received detailed information about the study and an informed consent form was obtained for each patient. All participants were screened by taking a detailed history and performing a thorough clinical and radiographic examination.

Thirty-four Children participated in the study having sixty carious mandibular second primary molars (unilateral and or/ bilateral). Patients were medically free with an age range from 5-7 years.

Patients were selected according to the following inclusion criteria: ${ }^{[10]}$

\section{Clinical inclusion criteria}

(1) Active carious lesion in dentin limited to the occluso-proximal surface of second mandibular primary molars.

(2) Absence of clinical diagnosis of pulp exposure, fistula, swelling of periodontal tissues, and/or abnormal tooth mobility

(3) Absence of clinical symptoms of irreversible pulpitis, such as spontaneous pain or sensitivity to pressure
(4) Complete caries removal would not risk pulp exposure, as determined by clinical assessment.

\section{Radiographic inclusion criteria}

Standardized periapical radiographs were taken and evaluated to complete the assessment for inclusion in the study.

(1) Absence of radiolucency at the inter-radicular (furcation) or periapical regions, or thickening of the periodontal spaces, that would indicate the presence of the irreversible pulp pathologies or necrosis

(2) Absence of internal or external root resorption.

\section{Sample size and allocation of experimental groups}

Based upon the results of Hübel \& Mejàre (2003) ${ }^{[11]}$ using clinical success as the primary outcome, the computed effect size (w) was found to be $(0.4)$, using alpha $(\alpha)$ level of $(5 \%)$ and Beta ( $\beta$ ) level of $(20 \%)$ i.e. power $=80 \%$; the minimum estimated sample size was a total of 60 restorations (20 restorations per group).

Sample size calculation was performed using IBM $^{\circledR}$ SPSS $^{\circledR}$ Sample Power ${ }^{\circledR}$ Release 3.0.1

Molars were anesthetized, and rubber dam isolation was performed by quadrants. Class II cavities were performed, according the carious lesion extension. Caries was removed completely from the cavo-surface margins and all lateral walls, including the pulp floor of the cavity preparation, with a sterile No. 330 high speed bur and water coolant. if complete excavation led to risk of pulp exposure, molars were excluded from the study. Enamel margins were not beveled. Contoured stainless steel matrix bands and wooden wedges were used. ${ }^{[10]}$ Molars were randomized for each of the three experimental groups according to the restorative material used, through a table of random numbers generated by the program: 
Sixty second mandibular primary molars indicated for class II preparation were divided into three equal groups. Molars were restored with three esthetic restorative materials according to manufacturer instructions as follows:

\section{Group (1) Compomer (Dyract AP)}

Group (2) Giomer (Beautifil II) (Shofu Inc, Japan)

\section{Group (3) Carbomer (GCP Glass Fill)}

\section{Materials used in the study:}

\begin{tabular}{|c|c|c|}
\hline $\begin{array}{c}\text { Material } \\
\text { name }\end{array}$ & Composition & Manufacturer \\
\hline $\begin{array}{c}\text { Dyract } \\
\text { AP }\end{array}$ & $\begin{array}{l}\text { - Urethane dimethacrylate (UDMA) } \\
\text { - Carboxylic acid modified dimeth- } \\
\text { acrylate (TCB resin) } \\
\text { - Camphorquinone } \\
\text { - Ethyl-4(dimethylamino)benzoate } \\
\text { - Butylated hydroxy toluene (BHT) } \\
\text { - UV stabilizer } \\
\text {-Strontium-alumino-sodium-fluoro- } \\
\text { phosphor-silicate glass } \\
\text { - Highly dispersed silicon dioxide } \\
\text { - Strontium fluoride - Iron oxide } \\
\text { pigments and titanium oxide pig- } \\
\text { ments }\end{array}$ & $\begin{array}{c}\text { Dentsply, } \\
\text { DeTrey, } \\
\text { Germany }\end{array}$ \\
\hline $\begin{array}{c}\text { Beautifil } \\
\text { II }\end{array}$ & $\begin{array}{l}\text { Base resin: Bis-GMA }(7.5 \mathrm{wt} \%) / \\
\text { TEGDMA (5 wt } \%) \text { resin Filler: } \\
\text { Multifunctional glass filler and S- } \\
\text { PRG (Surface Pre-Reacted Glass- } \\
\text { ionomer) filler based on fluroboro- } \\
\text { aluminosilicate glass. Filler loading: } \\
83.3 \mathrm{wt} \% \text { ( } 68.6 \mathrm{vol} \%) \text { Particle size } \\
\text { range: } 0.01 \mathrm{e} 4.0 \mathrm{~mm} \text { Mean particle } \\
\text { size: } 0.8 \mathrm{~mm} \text { DL-Camphorquinone }\end{array}$ & $\begin{array}{l}\text { Shofu, } \\
\text { Kyoto, } \\
\text { Japan }\end{array}$ \\
\hline $\begin{array}{c}\text { Glass Fill } \\
\text { (GCP) }\end{array}$ & $\begin{array}{l}\text { Powder: fluorosilicate glass treated } \\
\text { with poly(dialkylsiloxane) having } \\
\text { terminal hydroxyl groups, wherein } \\
\text { the alkyl groups contain } 1 \text { to } 4 \text { car- } \\
\text { bon atoms, fluoroapatite particles } \\
\text { Liquid: aqueous acid solution (poly- } \\
\text { acrylic acid and an inorganic acid). } \\
\text { Carbomer/fluoroapatite-enhanced } \\
\text { glass-ionomer cement 50\% vol. } \\
\text { Capsules primed and mixed, used } \\
\text { with a universal capsule gun }\end{array}$ & $\begin{array}{c}\text { Glass } \\
\text { Carbomer } \\
\text { Products, } \\
\text { Leiden, } \\
\text { Netherlands }\end{array}$ \\
\hline
\end{tabular}

\section{Group (1) Compomer:}

After cavity preparation, Prime \& Bond ${ }^{\circledR}$ NT and Dyract AP restorative (DeTrey/Dentsply, Konstanz, FRG) were used to restore the cavities. The primer was placed according to the manufacturer's instructions. The restorative material was applied in two incremental layers; the first layer filled the proximal box, while the second layer filled the rest of the cavity. Each layer was photopolymerized for 40 seconds with Elipar Visio II unit (ESPE GmbH, Seefeld, FRG). Following removal of the matrix band and wedge, the buccal and lingual margins of the proximal box received 40 seconds additional photopolymerization. The restorations were finished using 12-fluted carbide finishing burs (Jet Beavers, Morrisburg, Ontario, Canada) under water-spray and polished with the Enhance System (L.D. Caulk/ Dentsply Int., Milford, DE, USA). ${ }^{[12]}$

\section{Group (2) Giomer:}

After cavity preparation,FL-Bond II adhesive was applied according to manufacturer's instructions. The primer was applied on enamel and dentin and left undisturbed for $10 \mathrm{~s}$, dried with oil-free air, and then an even layer of bonding agent was applied on the entire cavity and light-cured for $10 \mathrm{~s}$ with halogen light curing unit. The proper shade of the material was selected, inserted and adapted with a flat-faced condenser into the proximal portion first, followed by the occlusal cavity in $2 \mathrm{~mm}$ increment and light cured for $20 \mathrm{~s}$ with the halogen light curing unit. Excess composite was finished and polished by "Dura White stones" and One Gloss Set. ${ }^{[13]}$

\section{Group (3) Carbomer:}

For the glass carbomer cement, the capsule is extruded in the proximal box first, then the rest of the cavity. GCP Gloss was applied with a bold instrument onto the restoration surface. Matrix band was then removed after clinical setting (3:30 mins). Finishing and polishing were performed after the final setting with extra-fine, friction grip diamonds under water- coalant. ${ }^{[8]}$ 
Molars were evaluated clinically at 3 months interval for one year using modified United States Public Health Service (USPHS) Criteria. ${ }^{[14]}$

\section{(1) Color matching:}

Alpha restoration is matched to the adjacent tooth structure in color.

Bravo mismatches are not outside the normal range of tooth color. Clinically acceptable.

Charliemismatches are outside the normal range of tooth color. Clinically unacceptable

\section{(2) Cavo surface discoloration:}

Alpha no discoloration is present.

Bravo discolorations have not penetrated along margin in pulpal direction.

Charlie discolorations have penetrated along margin in pulpal direction. Clinically unacceptable.

\section{(3) Postoperative hypersensitivity:}

Alpha postoperative hypersensitivity is absent.

Bravo postoperative hypersensitivity is present.

\section{(4) Anatomic form:}

Alpha restoration is continuous with existing anatomical form.

Bravo restoration is discontinuous with existing anatomical form, but missing material is not sufficient to expose dentine or base.

Charlie sufficient material is lost to expose dentine or base.

\section{(5) Margin integrity:}

Alpha no visible evidence of a crevice along the margin or the visible crevice is so small that the explorer just catches but doesn't "fall in"

Bravo visible evidence of a crevice along the margin into which the explorer penetrates, but no dentine or base exposed and/or dentine or base exposed.
Charlie the restoration is fractured or missing in part or in total.

\section{(6) Maintenance of interproximal contact:}

Alpha proximal contact is present.

Bravo Proximal contact is light but present.

Charlie No proximal contact.

\section{(7) Caries assessment:}

Alpha no caries is present at the margin of the restoration.

Bravo caries is present at the margin of the restoration, necessitating repair or replacement of the restoration.

\section{In the in-vitro part of the study}

\section{Sample size calculation}

Based upon the results of Yadav et al, (2012) using microleakage as the primary outcome, the computed effect size (f) was found to be (0.61), using alpha $(\alpha)$ level of $(5 \%)$ and Beta $(\beta)$ level of $(20 \%)$ i.e. power $=80 \%$; the minimum estimated sample size was a total of 30 specimens (10 specimens per group). Sample size calculation was performed using IBM ${ }^{\circledR}$ SPSS $^{\circledR}$ Sample Power ${ }^{\circledR}$ Release 3.0.1

Thirty non-carious second mandibular primary molars were collected. Surface debridement of all molars was done with hand instruments followed by storage in normal saline at room temperature till its use. Molars were randomly divided into three equal groups of 10 molars each. Standard class II cavities were prepared on all the 30 molars using bur no 330, using constant water-spray. Prepared cavities were then thoroughly cleaned with water and gently dried before the placement of the restoration. In each group the cavity was restored with its respective restorative material according to the manufacturer's instructions. ${ }^{[7]}$ 


\section{Group (1) Compomer (Dyract)}

\section{Group (2) Giomer (Beautifil)}

\section{Group (3) Carbomer (GCP Glass Fill).}

Samples were then subjected to thermocycling $\left(500\right.$ cycles, $\left.5^{\circ} \mathrm{C} / 55^{\circ} \mathrm{C}\right)$. Each molar was covered with nail polish except approximately within 1 $\mathrm{mm}$ of periphery of the restoration. The apices of molars were occluded with green stick compound to prevent leakage through root apices. Samples were immersed in $2 \%$ methylene blue dye (Supreme organization for drugs, Germany) for 24 hours at $37^{\circ} \mathrm{C}$. After removal from the dye, samples were thoroughly cleaned and rinsed under tap water until all the dye was removed from the surface. Specimens were sectioned mesio-distally with a low-speed diamond saw (D+Z, Diamant $\mathbf{G m b H}$ ) and evaluated for microleakage by means of dye penetration scoring under stereomicroscope at 40X magnification (Nikon Eclips E600, Tokyo, Japan) to measure the depth of the dye penetration at the two halves of the cavity and the mean was calculated. The restoration image was captured and transferred to a computer equipped with the image analysis software program (Image J 1.43U, National Institute of Health, USA) ${ }^{[15]}$ All scoring was carried out according to the following scoring criteria as presented in fig (1):

\section{A) Occlusal scoring:}

$0=$ no dye penetration

$1=$ dye penetration limited to enamel wall

$2=$ dye penetration including enamel and dentin before reaching the pulpal floor

$3=$ dye penetration less than half the distance of the pulpal floor

$4=$ dye penetration more than half of the pulpal floor or beyond.

\section{B) Gingival scoring:}

$0=$ no dye penetration

$1=$ dye penetration limited to enamel only

$2=$ dye penetration including enamel and dentin before reaching the axial wall.

$3=$ dye penetration reaching gingival half of the axial wall.

$4=$ dye penetration reaching the full length of the axial wall. ${ }^{[7]}$

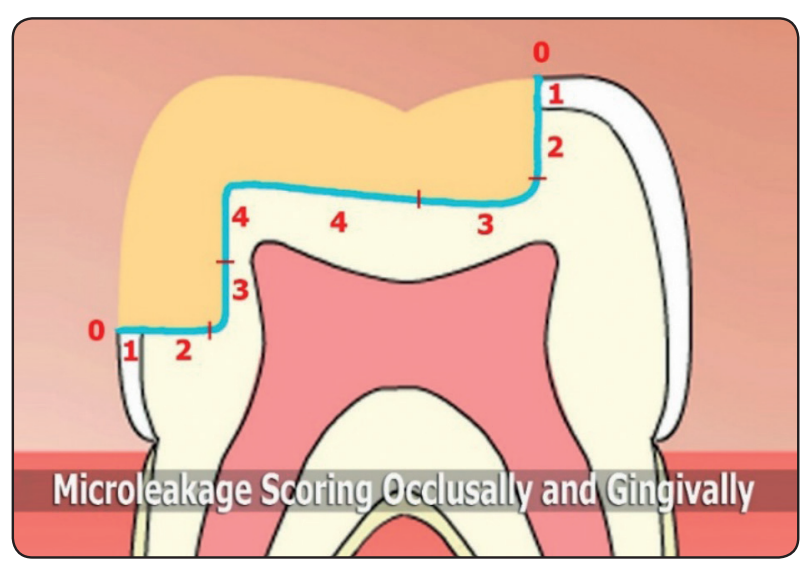

Fig (1): Microleakage scoring Occlusally and gingivally

\section{RESULTS}

Data were recorded and analyzed. Fisher's Exact test was used to compare between the three materials. Friedman's test was used to study the changes by time within each material.

Data were presented as frequencies (n) and percentages. The significance level was set at $\mathrm{P} \leq$ 0.05 . Statistical analysis was performed with IBM $^{\circledR}$ SPSS $^{\circledR}$ Statistics Version 20 for Windows.

\section{Demographic Data:}

There was no statistically significant difference regarding mean age values $(P$-value $=0.216)$ in the two groups. There was also no statistically 
significant difference between gender distributions $(P$-value $=0.909)$ in the two groups

TABLE (1): Mean, standard deviation (SD), frequencies (n), percentages and results of one-way ANOVA test, Chi-square test for comparisons of demographic data in the two groups

\begin{tabular}{ccccc}
\hline & $\begin{array}{c}\text { Compomer } \\
(\mathrm{n}=10)\end{array}$ & $\begin{array}{c}\text { Giomer } \\
(\mathrm{n}=11)\end{array}$ & $\begin{array}{c}\text { Carbomer } \\
(\mathrm{n}=13)\end{array}$ & $P$-value \\
\hline $\begin{array}{c}\text { Age (Years) } \\
\text { Mean (SD) }\end{array}$ & $5.9(0.9)$ & $6.2(0.8)$ & $5.6(0.8)$ & 0.216 \\
\hline $\begin{array}{c}\text { Gender [n (\%)] } \\
\text { Male }\end{array}$ & $4(40)$ & $6(54.5)$ & $6(46.2)$ & 0.909 \\
Female & $6(60)$ & $5(45.5)$ & $7(53.8)$ & \\
\hline
\end{tabular}

*: Significant at $P \leq 0.05$

\section{Color matching}

Regarding changes by time, Compomer group didn't present any change throughout the follow up period. Giomer showed a statistically significant increase in prevalence of Bravo score after 12 months. Carbomer showed a statistically significant increase in prevalence of Bravo score after 6,9 as well as 12 months and a statistically significant increase in Charlie score after 12 months.

\section{Surface discoloration}

Changes by time revealed that compomer didn't exhibit any change throughout the follow up period. Giomer showed a statistically significant increase in prevalence of Bravo score after 12 months. Carbomer showed a statistically significant increase in prevalence of Bravo score after 6,9 as well as 12 months and a statistically significant increase in Charlie score after 12 months.

\section{Post-operative hypersensitivity}

According to changes by time, Compomer didn't show any change throughout the follow up period. Giomer showed a statistically significant increase in prevalence of Bravo score after 12 months. Carbomer showed a statistically significant increase in prevalence of Bravo score after 6,9 and 12 months.

TABLE (2): Frequencies (n), percentages (\%) and results of comparisons related to color matching scores of three materials

\begin{tabular}{|c|c|c|c|c|c|c|c|c|}
\hline \multirow[b]{2}{*}{ Period } & \multirow[b]{2}{*}{ Score } & \multicolumn{2}{|c|}{ Compomer } & \multicolumn{2}{|c|}{ Giomer } & \multicolumn{2}{|c|}{ Carbomer } & \multirow{2}{*}{$\begin{array}{c}P \text {-value } \\
\text { (Between materials) }\end{array}$} \\
\hline & & $n$ & $\%$ & $n$ & $\%$ & $n$ & $\%$ & \\
\hline \multirow{3}{*}{3 months } & Alpha & 20 & 100.0 & 20 & 100.0 & 20 & 100.0 & \multirow{3}{*}{$\mathrm{NC}$} \\
\hline & Bravo & 0 & 0.0 & 0 & 0.0 & 0 & 0.0 & \\
\hline & Charlie & 0 & 0.0 & 0 & 0.0 & 0 & 0.0 & \\
\hline \multirow{3}{*}{6 months } & Alpha & 20 & 100.0 & 20 & 100.0 & 16 & 80.0 & \multirow{3}{*}{$0.030 *$} \\
\hline & Bravo & 0 & 0.0 & 0 & 0.0 & 4 & 20.0 & \\
\hline & Charlie & 0 & 0.0 & 0 & 0.0 & 0 & 0.0 & \\
\hline \multirow{3}{*}{9 months } & Alpha & 20 & 100.0 & 20 & 100.0 & 6 & 30.0 & \multirow{3}{*}{$<0.001 *$} \\
\hline & Bravo & 0 & 0.0 & 0 & 0.0 & 14 & 70.0 & \\
\hline & Charlie & 0 & 0.0 & 0 & 0.0 & 0 & 0.0 & \\
\hline \multirow{3}{*}{12 months } & Alpha & 20 & 100.0 & 16 & 80.0 & 0 & 0.0 & \multirow{3}{*}{$<0.001 *$} \\
\hline & Bravo & 0 & 0.0 & 4 & 20.0 & 16 & 80.0 & \\
\hline & Charlie & 0 & 0.0 & 0 & 0.0 & 4 & 20.0 & \\
\hline \multicolumn{2}{|c|}{$P$-value (Changes by time) } & \multicolumn{2}{|c|}{ NC } & \multicolumn{2}{|c|}{$0.007 *$} & \multicolumn{2}{|c|}{$<0.001 *$} & \\
\hline
\end{tabular}


TABLE (3): Frequencies (n), percentages (\%) and results of comparisons related to cavo-surface discoloration scores of three materials

\begin{tabular}{|c|c|c|c|c|c|c|c|c|}
\hline \multirow[b]{2}{*}{ Period } & \multirow[b]{2}{*}{ Score } & \multicolumn{2}{|c|}{ Compomer } & \multicolumn{2}{|c|}{ Giomer } & \multicolumn{2}{|c|}{ Carbomer } & \multirow{2}{*}{$\begin{array}{c}P \text {-value } \\
\text { (Between } \\
\text { materials) }\end{array}$} \\
\hline & & $n$ & $\%$ & $n$ & $\%$ & $n$ & $\%$ & \\
\hline \multirow{3}{*}{3 months } & Alpha & 20 & 100.0 & 20 & 100.0 & 20 & 100.0 & \multirow{3}{*}{$\mathrm{NC}$} \\
\hline & Bravo & 0 & 0.0 & 0 & 0.0 & 0 & 0.0 & \\
\hline & Charlie & 0 & 0.0 & 0 & 0.0 & 0 & 0.0 & \\
\hline \multirow{3}{*}{6 months } & Alpha & 20 & 100.0 & 20 & 100.0 & 16 & 80.0 & \multirow{3}{*}{$0.030 *$} \\
\hline & Bravo & 0 & 0.0 & 0 & 0.0 & 4 & 20.0 & \\
\hline & Charlie & 0 & 0.0 & 0 & 0.0 & 0 & 0.0 & \\
\hline \multirow{3}{*}{9 months } & Alpha & 20 & 100.0 & 20 & 100.0 & 6 & 30.0 & \multirow{3}{*}{$<0.001 *$} \\
\hline & Bravo & 0 & 0.0 & 0 & 0.0 & 14 & 70.0 & \\
\hline & Charlie & 0 & 0.0 & 0 & 0.0 & 0 & 0.0 & \\
\hline \multirow{3}{*}{12 months } & Alpha & 20 & 100.0 & 16 & 80.0 & 0 & 0.0 & \multirow{3}{*}{$<0.001 *$} \\
\hline & Bravo & 0 & 0.0 & 4 & 20.0 & 16 & 80.0 & \\
\hline & Charlie & 0 & 0.0 & 0 & 0.0 & 4 & 20.0 & \\
\hline \multicolumn{2}{|c|}{$P$-value (Changes by time) } & \multicolumn{2}{|c|}{ NC } & \multicolumn{2}{|c|}{$0.007 *$} & \multicolumn{2}{|c|}{$<0.001 *$} & \\
\hline
\end{tabular}

*: Significant at $P \leq 0.05$, NC: Not computed because the variable is constant

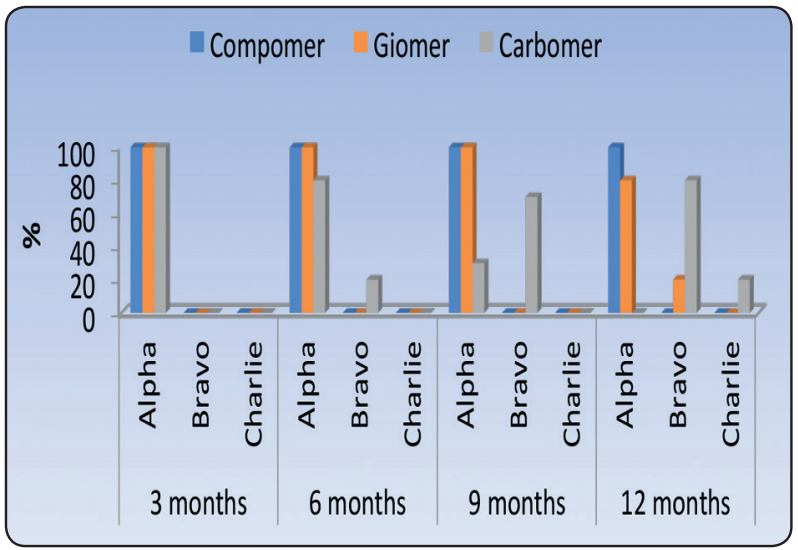

Fig. (2): Bar chart representing color matching scores of three materials

\section{Anatomic form}

Changes by time showed that compomer didn't present any change throughout the follow up period. Giomer showed a statistically significant increase in prevalence of Bravo score after 12 months. Carbomer showed a statistically significant increase in prevalence of Bravo score after 6, 9 as well as 12 months and a statistically significant increase in Charlie score after 12 months.

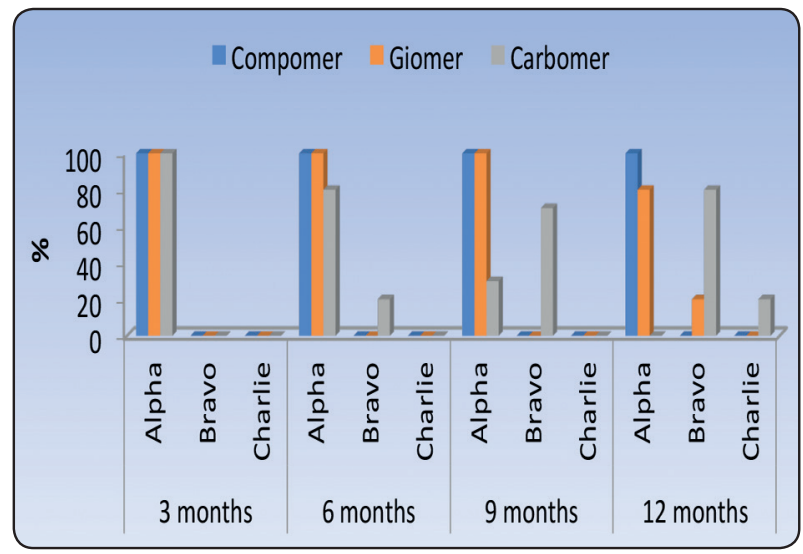

Fig. (3): Bar chart representing cavo-surface discoloration scores of three materials

\section{Margin integrity}

Changes by time represented as, Compomer didn't show any change throughout the follow up period. Giomer showed a statistically significant increase in prevalence of Bravo score after 12 months. Carbomer showed a statistically significant increase in prevalence of Bravo score after 6,9 as well as 12 months and a statistically significant increase in Charlie score after 12 months. 
TABLE (4): Frequencies (n), percentages (\%) and results of comparisons related to post-operative hypersensitivity scores of three materials

\begin{tabular}{|c|c|c|c|c|c|c|c|c|}
\hline \multirow{2}{*}{ Period } & \multirow{2}{*}{ Score } & \multicolumn{2}{|c|}{ Compomer } & \multicolumn{2}{|c|}{ Giomer } & \multicolumn{2}{|c|}{ Carbomer } & \multirow{2}{*}{$\begin{array}{c}P \text {-value } \\
\text { (Between materials) }\end{array}$} \\
\hline & & $n$ & $\%$ & $n$ & $\%$ & $n$ & $\%$ & \\
\hline \multirow{2}{*}{3 months } & Alpha & 20 & 100.0 & 20 & 100.0 & 20 & 100.0 & \multirow{2}{*}{$\mathrm{NC}$} \\
\hline & Bravo & 0 & 0.0 & 0 & 0.0 & 0 & 0.0 & \\
\hline \multirow{2}{*}{6 months } & Alpha & 20 & 100.0 & 20 & 100.0 & 20 & 100.0 & \multirow{2}{*}{ NC } \\
\hline & Bravo & 0 & 0.0 & 0 & 0.0 & 0 & 0.0 & \\
\hline \multirow{2}{*}{9 months } & Alpha & 20 & 100.0 & 20 & 100.0 & 6 & 30.0 & \multirow{2}{*}{$<0.001 *$} \\
\hline & Bravo & 0 & 0.0 & 0 & 0.0 & 14 & 70.0 & \\
\hline \multirow{2}{*}{12 months } & Alpha & 20 & 100.0 & 16 & 80.0 & 0 & 0.0 & \multirow{2}{*}{$<0.001 *$} \\
\hline & Bravo & 0 & 0.0 & 4 & 20.0 & 20 & 100.0 & \\
\hline \multicolumn{2}{|c|}{$P$-value (Changes by time) } & \multicolumn{2}{|c|}{ NC } & \multicolumn{2}{|c|}{$0.007 *$} & \multicolumn{2}{|c|}{$<0.001 *$} & \\
\hline
\end{tabular}

*: Significant at $P \leq 0.05$, NC: Not computed because the variable is constant

TABLE (5): Frequencies (n), percentages (\%) and results of comparisons related to anatomic form scores of three materials

\begin{tabular}{|c|c|c|c|c|c|c|c|c|}
\hline \multirow[b]{2}{*}{ Period } & \multirow[b]{2}{*}{ Score } & \multicolumn{2}{|c|}{ Compomer } & \multicolumn{2}{|c|}{ Giomer } & \multicolumn{2}{|c|}{ Carbomer } & \multirow{2}{*}{$\begin{array}{c}P \text {-value } \\
\text { (Between materials }\end{array}$} \\
\hline & & $n$ & $\%$ & $n$ & $\%$ & $n$ & $\%$ & \\
\hline \multirow{3}{*}{3 months } & Alpha & 20 & 100.0 & 20 & 100.0 & 20 & 100.0 & \multirow{3}{*}{$\mathrm{NC}$} \\
\hline & Bravo & 0 & 0.0 & 0 & 0.0 & 0 & 0.0 & \\
\hline & Charlie & 0 & 0.0 & 0 & 0.0 & 0 & 0.0 & \\
\hline \multirow{3}{*}{6 months } & Alpha & 20 & 100.0 & 20 & 100.0 & 16 & 80.0 & \multirow{3}{*}{$0.030 *$} \\
\hline & Bravo & 0 & 0.0 & 0 & 0.0 & 4 & 20.0 & \\
\hline & Charlie & 0 & 0.0 & 0 & 0.0 & 0 & 0.0 & \\
\hline \multirow{3}{*}{9 months } & Alpha & 20 & 100.0 & 20 & 100.0 & 6 & 30.0 & \multirow{3}{*}{$<0.001 *$} \\
\hline & Bravo & 0 & 0.0 & 0 & 0.0 & 14 & 70.0 & \\
\hline & Charlie & 0 & 0.0 & 0 & 0.0 & 0 & 0.0 & \\
\hline \multirow{3}{*}{12 months } & Alpha & 20 & 100.0 & 16 & 80.0 & 0 & 0.0 & \multirow{3}{*}{$<0.001 *$} \\
\hline & Bravo & 0 & 0.0 & 4 & 20.0 & 16 & 80.0 & \\
\hline & Charlie & 0 & 0.0 & 0 & 0.0 & 4 & 20.0 & \\
\hline \multicolumn{2}{|c|}{$P$-value (Changes by time) } & \multicolumn{2}{|c|}{ NC } & \multicolumn{2}{|c|}{$0.007 *$} & \multicolumn{2}{|c|}{$<0.001 *$} & \\
\hline
\end{tabular}

*: Significant at $P \leq 0.05, N C$ : Not computed because the variable is constant

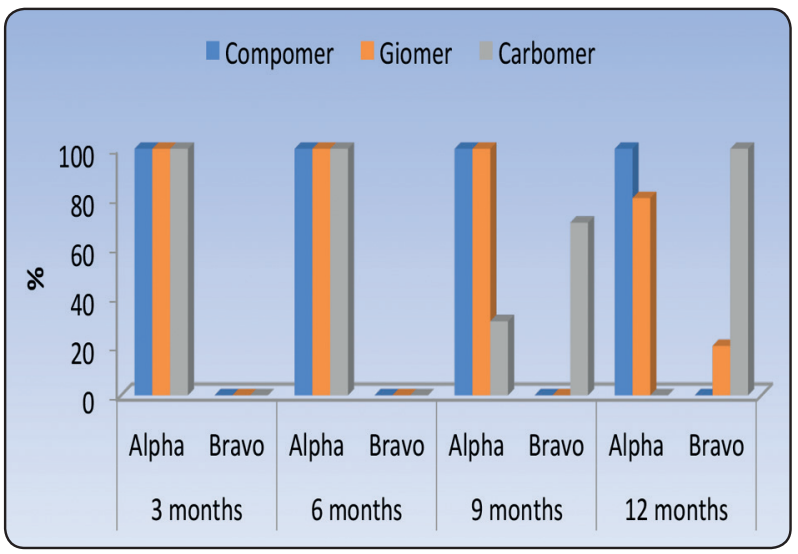

Fig. (4): Bar chart representing post-operative hypersensitivity scores of three materials

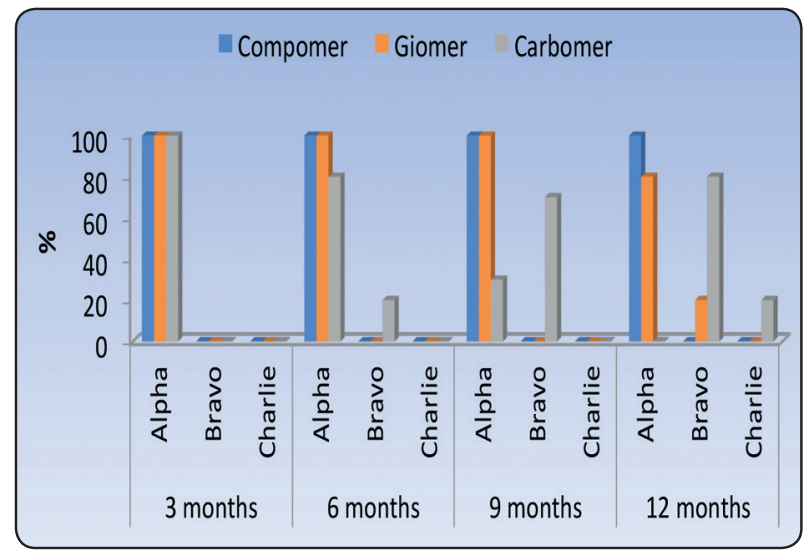

Fig. (5): Bar chart representing anatomic form scores of three materials 
TABLE (6): Frequencies (n), percentages (\%) and results of comparisons related to margin integrity scores of three materials

\begin{tabular}{|c|c|c|c|c|c|c|c|c|}
\hline \multirow[b]{2}{*}{ Period } & \multirow[b]{2}{*}{ Score } & \multicolumn{2}{|c|}{ Compomer } & \multicolumn{2}{|c|}{ Giomer } & \multicolumn{2}{|c|}{ Carbomer } & \multirow{2}{*}{$\begin{array}{c}P \text {-value } \\
\text { (Between materials) }\end{array}$} \\
\hline & & $n$ & $\%$ & $n$ & $\%$ & $n$ & $\%$ & \\
\hline \multirow{3}{*}{3 months } & Alpha & 20 & 100.0 & 20 & 100.0 & 20 & 100.0 & \multirow{3}{*}{$\mathrm{NC}$} \\
\hline & Bravo & 0 & 0.0 & 0 & 0.0 & 0 & 0.0 & \\
\hline & Charlie & 0 & 0.0 & 0 & 0.0 & 0 & 0.0 & \\
\hline \multirow{3}{*}{6 months } & Alpha & 20 & 100.0 & 20 & 100.0 & 16 & 80.0 & \multirow{3}{*}{$0.030 *$} \\
\hline & Bravo & 0 & 0.0 & 0 & 0.0 & 4 & 20.0 & \\
\hline & Charlie & 0 & 0.0 & 0 & 0.0 & 0 & 0.0 & \\
\hline \multirow{3}{*}{9 months } & Alpha & 20 & 100.0 & 20 & 100.0 & 6 & 30.0 & \multirow{3}{*}{$<0.001 *$} \\
\hline & Bravo & 0 & 0.0 & 0 & 0.0 & 14 & 70.0 & \\
\hline & Charlie & 0 & 0.0 & 0 & 0.0 & 0 & 0.0 & \\
\hline \multirow{3}{*}{12 months } & Alpha & 20 & 100.0 & 16 & 80.0 & 0 & 0.0 & \multirow{3}{*}{$<0.001 *$} \\
\hline & Bravo & 0 & 0.0 & 4 & 20.0 & 16 & 80.0 & \\
\hline & Charlie & 0 & 0.0 & 0 & 0.0 & 4 & 20.0 & \\
\hline \multicolumn{2}{|c|}{$P$-value (Changes by time) } & \multicolumn{2}{|c|}{$\mathrm{NC}$} & \multicolumn{2}{|c|}{$0.007 *$} & \multicolumn{2}{|c|}{$<0.001 *$} & \\
\hline
\end{tabular}

*: Significant at $P \leq 0.05, N C$ : Not computed because the variable is constant

TABLE (7): Frequencies (n), percentages (\%) and results of comparisons related to maintenance of interproximal contact scores of three materials

\begin{tabular}{|c|c|c|c|c|c|c|c|c|}
\hline \multirow[b]{2}{*}{ Period } & \multirow[b]{2}{*}{ Score } & \multicolumn{2}{|c|}{ Compomer } & \multicolumn{2}{|c|}{ Giomer } & \multicolumn{2}{|c|}{ Carbomer } & \multirow{2}{*}{$\begin{array}{c}P \text {-value } \\
\text { (Between materials) }\end{array}$} \\
\hline & & $n$ & $\%$ & $n$ & $\%$ & $n$ & $\%$ & \\
\hline \multirow{3}{*}{3 months } & Alpha & 20 & 100.0 & 20 & 100.0 & 20 & 100.0 & \multirow{3}{*}{$\mathrm{NC}$} \\
\hline & Bravo & 0 & 0.0 & 0 & 0.0 & 0 & 0.0 & \\
\hline & Charlie & 0 & 0.0 & 0 & 0.0 & 0 & 0.0 & \\
\hline \multirow{3}{*}{6 months } & Alpha & 20 & 100.0 & 20 & 100.0 & 16 & 80.0 & \multirow{3}{*}{$0.030 *$} \\
\hline & Bravo & 0 & 0.0 & 0 & 0.0 & 4 & 20.0 & \\
\hline & Charlie & 0 & 0.0 & 0 & 0.0 & 0 & 0.0 & \\
\hline \multirow{3}{*}{9 months } & Alpha & 20 & 100.0 & 20 & 100.0 & 6 & 30.0 & \multirow{3}{*}{$<0.001 *$} \\
\hline & Bravo & 0 & 0.0 & 0 & 0.0 & 14 & 70.0 & \\
\hline & Charlie & 0 & 0.0 & 0 & 0.0 & 0 & 0.0 & \\
\hline \multirow{3}{*}{12 months } & Alpha & 20 & 100.0 & 16 & 80.0 & 0 & 0.0 & \multirow{3}{*}{$<0.001 *$} \\
\hline & Bravo & 0 & 0.0 & 4 & 20.0 & 16 & 80.0 & \\
\hline & Charlie & 0 & 0.0 & 0 & 0.0 & 4 & 20.0 & \\
\hline \multicolumn{2}{|c|}{$P$-value (Changes by time) } & & & \multicolumn{2}{|c|}{$0.007 *$} & \multicolumn{2}{|c|}{$<0.001 *$} & \\
\hline
\end{tabular}

*: Significant at $P \leq 0.05$, NC: Not computed because the variable is constant 


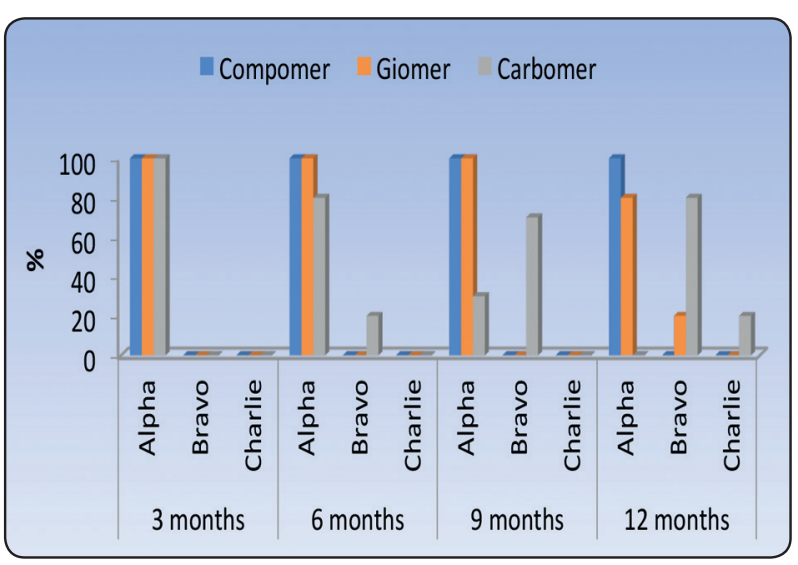

Fig. (6): Bar chart representing margin integrity scores of three materials

\section{Maintenance of interproximal contact}

Regarding the changes by time, Compomer didn't show any change throughout the follow up period. Giomer showed a statistically significant increase in prevalence of Bravo score after 12 months. Carbomer showed a statistically significant increase in prevalence of Bravo score after 6,9 as well as 12 months and a statistically significant increase in Charlie score after 12 months.

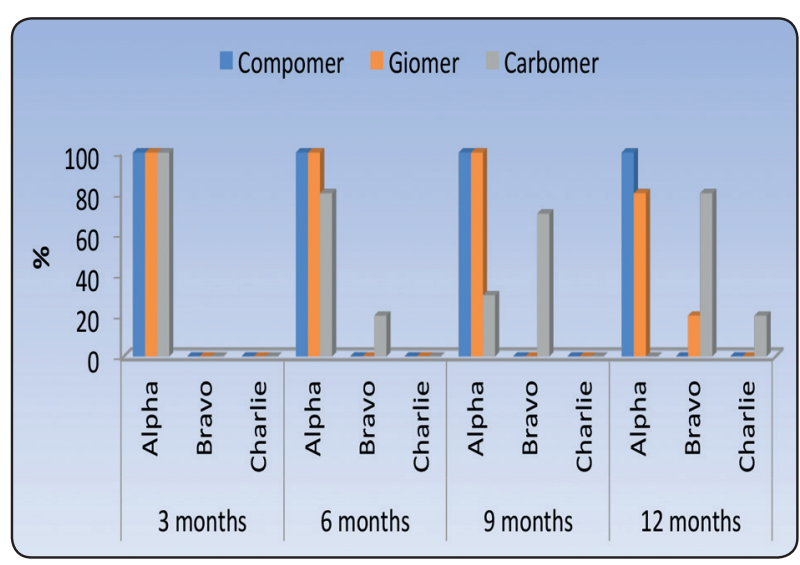

Fig. (7): Bar chart representing maintenance of interproximal contact scores of three materials

\section{Caries assessment}

As regards the changes by time, Compomer didn't show any change throughout the follow up period. Giomer showed a statistically significant increase in prevalence of Bravo score after 12 months. Carbomer showed a statistically significant increase in prevalence of Bravo score after 6,9 as well as 12 months.

TABLE (8): Frequencies (n), percentages (\%) and results of comparisons related to caries assessment scores of three materials

\begin{tabular}{|c|c|c|c|c|c|c|c|c|}
\hline \multirow[b]{2}{*}{ Period } & \multirow[b]{2}{*}{ Score } & \multicolumn{2}{|c|}{ Compomer } & \multicolumn{2}{|c|}{ Giomer } & \multicolumn{2}{|c|}{ Carbomer } & \multirow{2}{*}{$\begin{array}{c}P \text {-value } \\
\text { (Between materials) }\end{array}$} \\
\hline & & $n$ & $\%$ & $n$ & $\%$ & $n$ & $\%$ & \\
\hline \multirow{2}{*}{3 months } & Alpha & 20 & 100.0 & 20 & 100.0 & 20 & 100.0 & \multirow{2}{*}{$\mathrm{NC}$} \\
\hline & Bravo & 0 & 0.0 & 0 & 0.0 & 0 & 0.0 & \\
\hline \multirow{2}{*}{6 months } & Alpha & 20 & 100.0 & 20 & 100.0 & 16 & 80.0 & \multirow{2}{*}{$0.030 *$} \\
\hline & Bravo & 0 & 0.0 & 0 & 0.0 & 4 & 20.0 & \\
\hline \multirow{2}{*}{9 months } & Alpha & 20 & 100.0 & 20 & 100.0 & 6 & 30.0 & \multirow{2}{*}{$<0.001 *$} \\
\hline & Bravo & 0 & 0.0 & 0 & 0.0 & 14 & 70.0 & \\
\hline \multirow{2}{*}{12 months } & Alpha & 20 & 100.0 & 16 & 80.0 & 0 & 0.0 & \multirow{2}{*}{$<0.001 *$} \\
\hline & Bravo & 0 & 0.0 & 4 & 20.0 & 20 & 100.0 & \\
\hline \multicolumn{2}{|c|}{$P$-value (Changes by time) } & \multicolumn{2}{|c|}{ NC } & \multicolumn{2}{|c|}{$0.007 *$} & \multicolumn{2}{|c|}{$<0.001 *$} & \\
\hline
\end{tabular}

*: Significant at $P \leq 0.05, N C$ : Not computed because the variable is constant 


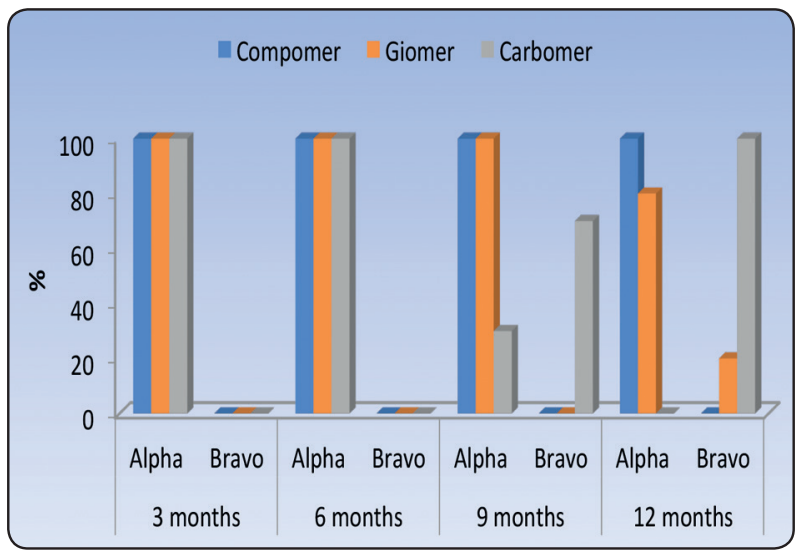

Fig. (8): Bar chart representing caries assessment scores of three materials

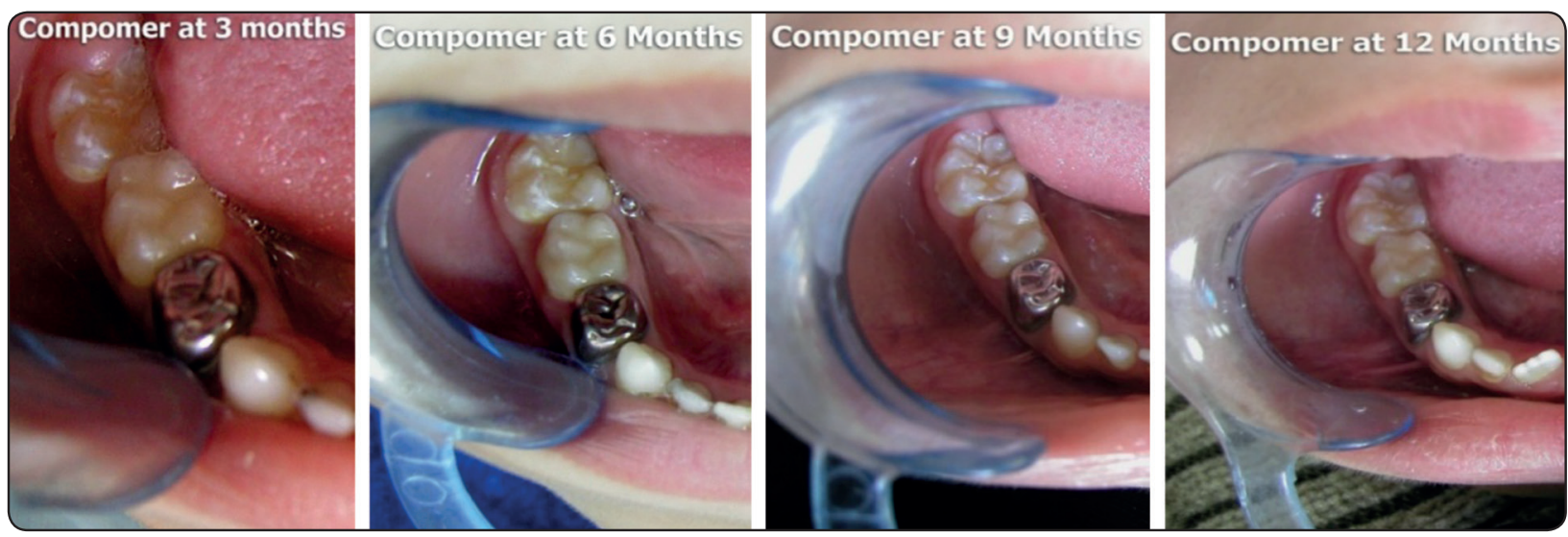

Fig. (9) Compomer at different time intervals

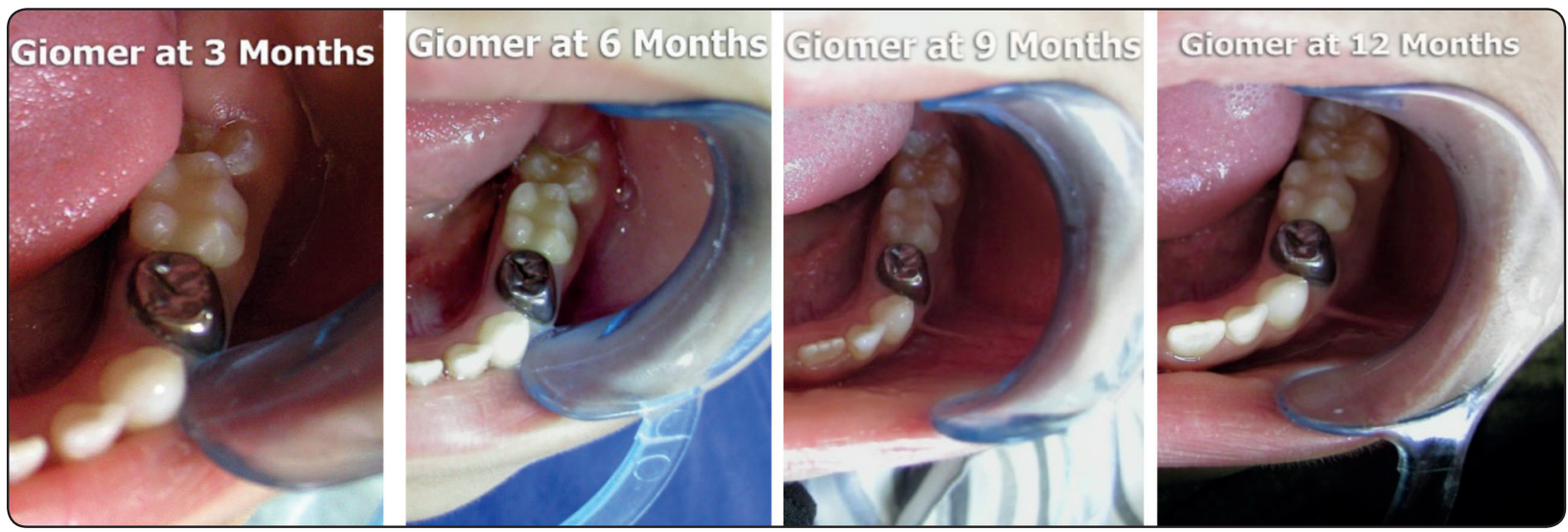

Fig. (10) Giomer at different time intervals 


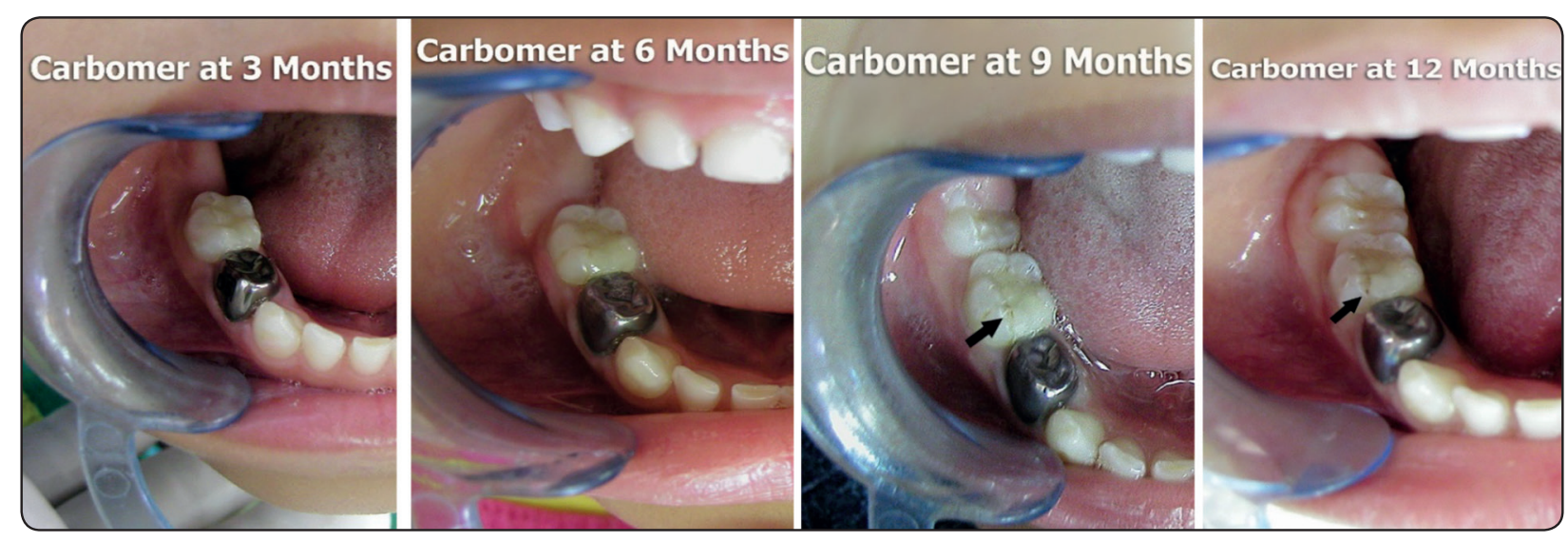

Fig (11) Carbomer at different time intervals

\section{Microleakage scores}

Occlusal microleakage presented statistically significant difference between the three materials. Compomer showed the highest prevalence of Score 0 while Carbomer showed the highest prevalence of scores 1 and 2.

While for gingival microleakage, there was a statistically significant difference between the three materials. Compomer showed the highest prevalence of Score 1 while Carbomer showed the

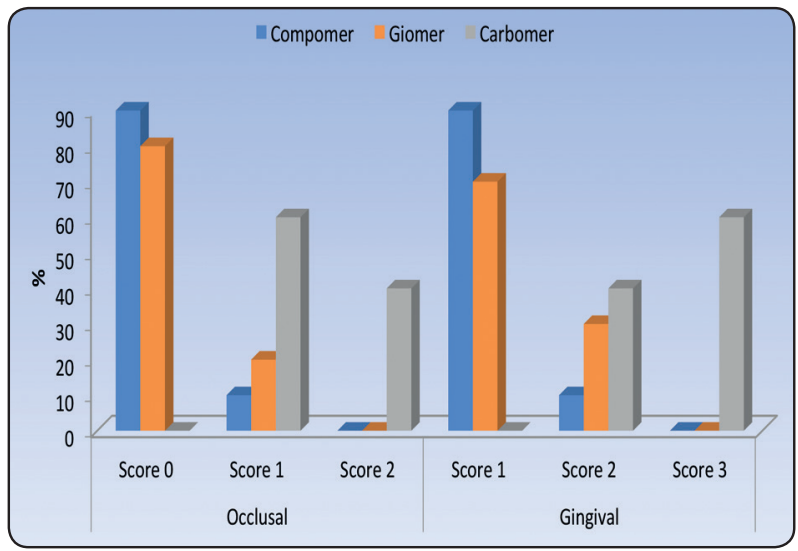

Fig. (12): Bar chart representing micro-leakage scores of three materials highest prevalence of scores 2 and 3.

TABLE (9): Frequencies (n), percentages (\%) and results of comparisons between microleakage scores of three materials

\begin{tabular}{|c|c|c|c|c|c|c|c|c|}
\hline \multirow[b]{2}{*}{ Site } & \multirow[b]{2}{*}{ Score } & \multicolumn{2}{|c|}{ Compomer } & \multicolumn{2}{|c|}{ Giomer } & \multicolumn{2}{|c|}{ Carbomer } & \multirow{2}{*}{$\begin{array}{c}P \text {-value } \\
\text { (Between materials) }\end{array}$} \\
\hline & & $n$ & $\%$ & $n$ & $\%$ & $n$ & $\%$ & \\
\hline \multirow{3}{*}{ Occlusal } & Score 0 & 9 & 90.0 & 8 & 80.0 & 0 & 0.0 & \multirow{3}{*}{$<0.001 *$} \\
\hline & Score 1 & 1 & 10.0 & 2 & 20.0 & 6 & 60.0 & \\
\hline & Score 2 & 0 & 0.0 & 0 & 0.0 & 40 & 40.0 & \\
\hline \multirow{3}{*}{ Gingival } & Score 1 & 9 & 90.0 & 7 & 70.0 & 0 & 0.0 & \multirow{3}{*}{$<0.001 *$} \\
\hline & Score 2 & 1 & 10.0 & 3 & 30.0 & 4 & 40.0 & \\
\hline & Score 3 & 0 & 0.0 & 0 & 0.0 & 6 & 60.0 & \\
\hline
\end{tabular}

*: Significant at $P \leq 0.05$ 


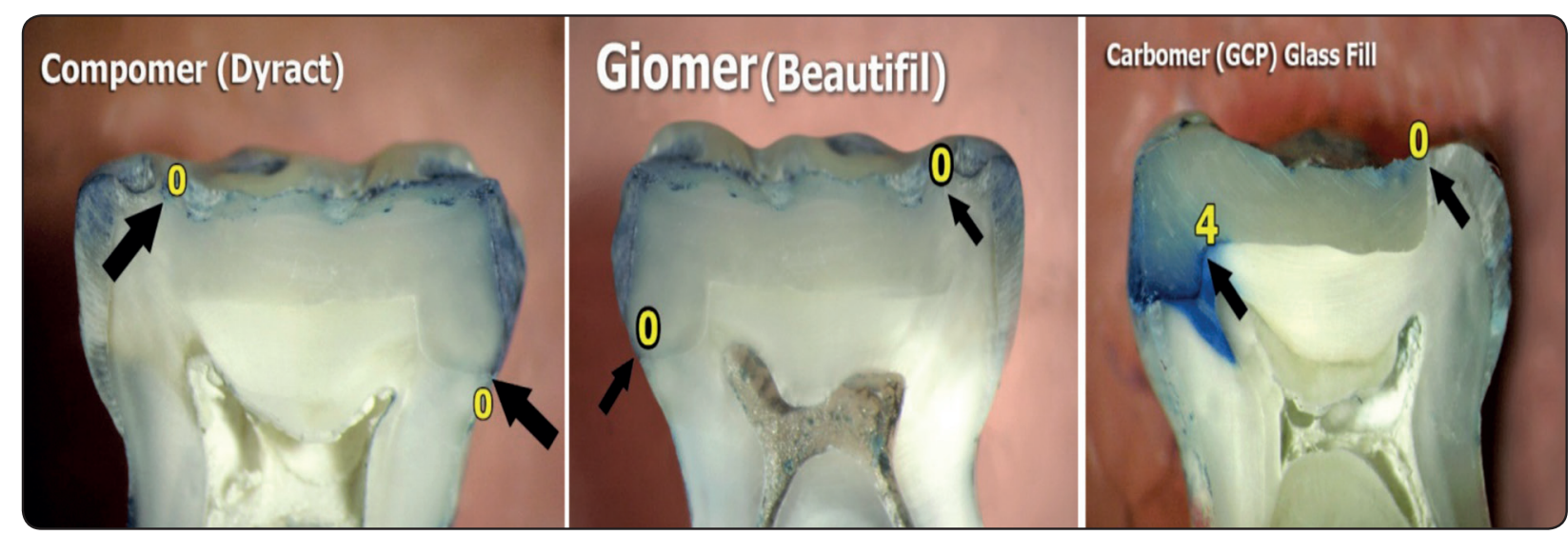

Fig. (13) Microleakage scoring for Compomer, Giomer and Carbomer

\section{DISCUSSION}

Primary teeth in clinical studies offer a real information source about the clinical performance of restorations as a result of physical and chemical events in the oral environment. Primary teeth have a well-defined life cycle in the oral cavity, their use has an added advantage that, it contradicts the violation of ethical issues involved in research.

Adhesive restorative techniques and materials development contributed the minimal invasive concept confining removal of infected carious tissue without the need for additional retention. Several technical modifications were incorporated into the development of resin-based materials. One of the concerns of the manufacturers is the control of the polymerization shrinkage that occurs in these materials to achieve lasting marginal integrity. Another concern, especially in pediatric dentistry, children's behavior that entails shorter time procedures. Technique-sensitivity and timeconsuming procedure are well-known disadvantages in traditional resin composite restorations, which increase the chances to apply glass-ionomer cements, that are less technique-sensitive and can be placed in only one increment. ${ }^{[12]}$

Polyacid-modified resin composites have been introduced as materials for the conservative restoration of primary teeth based on the results of clinical trials. Clinical studies investigate the clinical performance of restorations in oral conditions, show the potential of a restorative material for specific clinical applications and reveal the main causes of restoration failures. ${ }^{[16]}$ The current study was conducted to investigate the clinical performance of compomer, Giomer and Carbomer in class II restorations of primary molars.

The clinical success of the restorations, as measured by color match, anatomic form, marginal integrity, marginal discoloration, post-operative hypersensitivity, maintenance of interproximal contact and secondary caries, was acceptable. Many authors considered Compomer restorations successful esthetic alternative to conventional amalgam for class II restorations in primary molars over the time interval studied ${ }^{[6,17]}$. Ease of manipulation a prime advantage of compomers was attributed to their consistency, easier application and contouring. Less time is therefore required for finishing and final polishing. These features are especially beneficial when treating children. ${ }^{[18]}$

On the other hand, different studies reported that, when different compomer materials were used, the clinical failure rate ranged from 0 to $42 \%$. ${ }^{[17,19]}$

Papagiannoulis et al. ${ }^{[12]}$ reported that the highest retention rate with Dyract restorations was $100 \%$ as presented in the present study, the cavity design in 
that study followed Black's principles, which may explain the high retention rates obtained.

The findings in the current study is consistent with Duggal et al, who reported the superior performance of compomer restoration regarding marginal integrity in primary molar restorations. The results of their study, showed that anatomic form of compomer was better with longer evaluation period (24 months). ${ }^{[20]}$

Giomer material has been introduced as the true hybridization of glass ionomer and composite resin, containing surface pre-reacted glass ionomer (S-PRG) filler particles within a resin matrix. Giomer composite materials have been chosen in this study as it they provide the fluoride release, recharge of glass ionomers, esthetics, physical and handling properties of composite resins. ${ }^{[21]}$ Further, $\mathrm{S}-\mathrm{PRG}$ filler particles in giomer was reported to act as fluoride reservoir that recharge with brushing or rinsing with fluoridated products. ${ }^{[22,23]}$ Giomers form an acid-resistant film, resist plaque formation as it inhibits bacterial adhesion. ${ }^{23,24]}$

In the present study, the evaluation of marginal adaptation recorded 4 Bravo scores out of the twenty restorations of Beautifil II restorations at 12-month evaluation period. Although Beautifil II material has high filler content without bonding of the resin with S-PRG filler might be responsible for decreased marginal adaptation and surface morphology, increased surface roughness and marginal discoloration in Beautifil II material. Moreover, Beautifil II had the high filler loading; any dissolution of the resin matrix would lead to greater exposure of the irregularly arranged filler particles resulting in rougher surfaces which easily stained by mechanical absorption. ${ }^{[25]}$ Marginal defects and/or marginal staining are signs of bond degradation [26] and fatigue of restorative materials due to repeated occlusal load and thermal stresses ${ }^{[27]}$.

Glass carbomers are a type of glass ionomer cements, which have nano-sized Fluorapatite and Hydroxyapatite added to their composition. The actual glass phase consists of an aluminosilicate glass; however, it is shown that this glass contains less network modifying ions and thus less non-bridging oxygens ${ }^{[28]}$. During setting, a large amount of the hydroxyapatite can be dissolved and consumed by the PAA; thus, only a small amount of apatite (Ap) is present to induce remineralization. Recently, glass carbomers are commercialized under the name of GCP Glass Fill, this material may be an interesting subject of research, certainly its bioactive properties as the manufacturer claims this material to have remineralizing properties. If this is the case, GCP Glass Fill could be an interesting reference material for further bioactivity studies. This material comes with very specific guidelines, which state that on top of the material, a gloss should be used, and that the material should be thermo cured. The GCP gloss is a silicone-based coat. It protects the surface from exposure to moisture and saliva in the first reaction step as well as prevents dehydration in the second phase ${ }^{[29]}$. In order to improve the mechanical properties, application of heat energy can be used so that the cement sets "on command".

In the current study, Carbomer started to present bravo scores at 6 months that incurred to Charlie scores at 9 and 12 months intervals, deterioration in the clinical performance of the material was noticed regarding colour match, anatomic form, marginal integrity, marginal discoloration, post-operative hypersensitivity, maintenance of interproximal contact and secondary caries, was not acceptable. The results could be attributed to the nature of the material as it is basically GICs which are moisture-sensitive restorative materials. During the setting stage, both water uptake and water loss can compromise the physical properties and marginal sealing of the restoration. Thus, following the placement of GIC, surface protection must be provided to maintain the water balance of restorations for the first $24 \mathrm{~h}$. ${ }^{[8]}$ As for the glass carbomer product, the manufacturer provides a patented carbon-silicon fluid (referred to as "Surface Gloss") to moisten the surface of the 
filling during modelling and to seal the restoration surface.

It should be noted that the sealed glass carbomer material showed higher values of marginal deterioration than the compomer material. In the present study, the marginal integrity of the glass carbomer restorations was differentially affected. Chen et al, claimed the presence of minor surface cracks in the marginal and central regions of the restorations. In the glass carbomer group, catastrophic internal and surface crack lines, resembling ice cracks, were evident. The surface gloss was applied over the newly placed glass carbomer sealant, but thereafter, a special carving instrument was used to remove the excess material, which also might have removed some or most of the surface sealant before photopolymerization. ${ }^{[30]}$

An important goal in restorative dentistry is the control of marginal leakage which may occur because of dimensional changes or lack of adaptation of the restorative materials to the cavity preparation. These interfacial gaps may lead to recurrent caries and pulpal pathosis ${ }^{\left[{ }^{[31]}\right.} \mathrm{It}$ is apparent that microleakage around restorations is a series of phenomena and not a single entity. Although ionic charge and chemical reactivity of diffusing fluids have a part in marginal leakage, the physical and chemical nature of restorative materials and the clinical skills of the operator play equally crucial roles. It must be recognized that application of the restorative materials in vivo is more difficult than their application in vitro on extracted teeth. An adequate seal in vivo is unquestionably and undoubtedly difficult to obtain. In the present study, microleakage was seen to some extent with almost all the dental restorative materials. Gladys et al suggested earlier that microleakage can be expected with all the dental restorative materials developed till date. ${ }^{[32]}$

In the current study, it was found that the least microleakage occurred in the Compomer group and the maximum microleakage scores were detected in the carbomer group. A possible explanation for the lower microleakage scores may be the three-dimensional structure and low modulus of elasticity which may have reduced polymerization shrinkage. ${ }^{[33]}$ In addition, Jain reported that reduced shrinkage, results in requiring less adhesion power of the adhesive and especially after long time less marginal gap is expected. ${ }^{[34]}$

In the present study compomer had comparatively decreased marginal leakage which was consistent with the studies reported earlier by Welbury et al ${ }^{[35]}$ Sikri $\boldsymbol{V}$ et al ${ }^{[36]}$ and Mali P et al ${ }^{[1]}$ who compared microleakage of glass ionomer, composite resin and compomers. It was concluded that microleakage was evident in all restorative materials, with glass ionomer showing maximum leakage followed by composite and compomers demonstrated the best results with minimum leakage which is consistent with the results of the current study.

In the present study carbomer had greater microleakage score than giomer and compomer which could be due to the immediate finishing/ polishing procedure which was employed in our study according to the manufacturer's instructions. It has been suggested by Yap et al ${ }^{[37]}$ that in addition to surface roughness, immediate finishing/ polishing could compromise the marginal seal of glass ionomer-based materials to tooth. Although immediate finishing/polishing did not affect the marginal seal to dentin, it increased microleakage at enamel margins.

\section{CONCLUSIONS}

- Compomer and Giomer groups showed statistically significant clinical success than the Carbomer group according to USPHS criteria.

- Microleakage at the gingival margin in all groups was statistically significantly higher than at the occlusal surfaces. 
- Compomer and Giomer showed the least microleakage scores in Class II cavity preparations.

- Microleakage was statistically significant in Carbomer (GCP Glass Fill) group.

\section{Recommendations}

When esthetics and durability are of prime importance, Compomer and Giomer serve as advocated esthetic restorative materials in class II in primary molars.

\section{REFERENCES}

1. Mali P, Deshpande S, Singh A. Microleakage of restorative materials: an in vitro study. J Indian Soc Pedod Prev Dent 2006 Mar;24(1):15-18.

2. Fuks AB, Araujo FB, Osorio LB, Hadani PE, Pinto AS. Clinical and radiographic assessment of class II esthetic restorations in primary molars. Pediatr Dent 2000; 22:479485 .

3. Fuks AB, Araujo FB, Donly KJ, Cervantes M. Reliability of different techniques to assess marginal defects of class II restorations in retrieved primary molars: A visual-tactile, SEM, dye penetration and polarized light microscopy study. Pediatr Dent 2002; 19: 6-15.

4. Araujo FB, Mariath AAS, Bressani AEL, Casagrande L, Wienandts P. Treatment of caries lesions in primary teeth. Pediatric dentistry: Fundamentals for clinical practice. 2nd ed, São Paulo: Premier, 2005; 163-214.

5. Yengopal V, Harneker SY, Patel N, Siegfried N. Dental fillings for the treatment of caries in the primary dentition. Cochrane Database Syst Rev 2009; 15: CD004483.

6. Gross L C, Griffen A L., Casamassimo PS. Compomers as class II restorations in primary molars. Pediatr Dent 2001;1: 23-27.

7. Yadav G, Rehani U, Rana V. A Comparative Evaluation of Marginal Leakage of Different Restorative Materials in Deciduous Molars: An in vitro Study. Int J Clinic Pediatr Dent, 2012;5(2):101-107.

8. Cehreli S B, Tirali R. E, Yalcinkaya Z, Cehreli Z C. Microleakage of newly developed glass carbomer cement in primary teeth. Eur J Dent 2013; 7:15-21.
9. Burke FJ, Fleming GJ, Owen FJ, Watson DJ. Materials for restoration of primary teeth: Glass ionomer derivatives and compomers. Dent Update, 2002 Jan-Feb;29(1):10-14, 16-17.

10. Casagrande L, Dalpian D M, Ardenghi T M, Zanatta F B, Balbinot C E A, García-Godoy F, De Araujo F B. Randomized clinical trial of adhesive restorations in primary molars. 18-month results. Am J Dent, 2013; 26:351-355.

11. Hübel S, Mejàre I. Conventional versus resin-modified glass-ionomer cement for Class II restorations in primary molars. A 3-year clinical study. Inter J Paed Dent 2003; 13:2-8.

12. Papagiannoulis L, Kakaboura A., Pantaleon F , Kavvadia K. Clinical evaluation of a polyacid-modified resin composite (compomer) in Class II restorations of primary teeth: a two-year follow-up study. Pediatr Dent, 1999; 21:232-235.

13. Abdel-Karim UM, El-Eraky M, Etman WM. Three-year clinical evaluation of two nano-hybrid Giomer restorative composites. Tanta Dent J ,2014(11):213-222.

14. Cvar J F, Ryje G. Reprint of criteria for the clinical evaluation of dental restorative materials . clinic oral invests, 2005; 9(4):215-232.

15. Navarro RS, Gouw-Soares S, Cassoni A, Haypek P, Zezell DM, de Paula E C. The influence of erbium: yttrium-aluminum-garnet laser ablation with variable pulse width on morphology and microleakage of composite restorations. Lasers Med Sci. 2010; 25:881-9.

16. Kilpatrick NM: Durability of restorations in primary molars. J Dent 1992; 21:67-73.

17. Turgut MD, Tekçiçek M, Ölmez S: Clinical evaluation of a polyacid-modified resin composite under different conditioning methods in primary teeth. Oper Dent 2004; 29: $515-523$.

18. Kramer N, Frankenberger R: Compomers in restorative therapy of children: a literature review. Int J Paediatr Dent 2007; 17: 2 -9.

19. Anderson-Wenckert IE, Folkesson UH, Van Dijken JWV: Durability of a polyacid-modified composite resin (compomer) in primary molars. A multicenter study. Acta Odont Scand 1997; 55: 2 55-260.

20. Duggal MS, Toumba K, Sharma NK. Clinical performance of compomer and amalgam for the interproximal restoration of primary molars: A 24-month evaluation. Br Dent J 2002; 193:339-42. 
21. Tay F, Pashely E, Huang C, Hashimoto M, Sano H, Salmes $\mathrm{R}$ et al. The glass ionomer phase in resin-based restorative materials. J Dent Res;2001; 80:1808-12.

22. Okuyama K, Okuyama YI, Pereira PN, Miguez PA, Komatsu H, Sano H. Fluoride release and uptake by various dental materials after fluoride application. Am J Dent 2006; 19:123-7.

23. Dhull KS, Nandlal B. Comparative evaluation of fluoride release from PRG-composites and compomer on application of topical fluoride. J Indian Soc Pedod Prev Dent 2009;27(1):27-32.

24. Fujimoto Y, Iwasa M, Murayama R, Miyazaki M, Nagafuji A, Nakatsuka T. Detection of ions released from S-PRG fillers and their modulation effect. Dent Mater 2010;29(4):1-6.

25. Bagheri R, Burrow M, Tyas M. Influence of food simulating solutions and surface finish on susceptibility to staining of aesthetic restorative materials. J Dent 2005; 33:389-98.

26. Peumans M, De Munck J, Van Landuyt K, Lambrechts P, Van Meerbeek B. Five-year clinical effectiveness of a twostep self-etching adhesive. J Adhes Dent 2007; 9:7-10.

27. Kubo S, Yokota H, Yokota HA, Hayashi Y. Three-year clinical evaluation of a flowable and a hybrid resin composite in non-carious cervical lesions. J Dent 2010; 38:191-200.

28. Zainuddin N, Karpukhina N, Law RV, Hill RG. Characterization of a remineralizing Glass Carbomer(R) ionomer cement by MAS-NMR spectroscopy. Dent Mater. 2012;28(10):1051-8.
29. Menne-Happ U, Ilie N. Effect of gloss and heat on the mechanical behaviour of a glass carbomer cement. J Dent. 2013;41(3):223-30

30. Chen X, Cuijpers V, Fan M, Frencken JE. Marginal leakage of two newer glass-ionomer-based sealant materials assessed using micro-CT. J Dent 2010; 38:731-735.

31. Morabito A, Defabianis P. The marginal seal of various restorative materials in primary molars. J Clin Pediatr Dent 1997 Fall; 22(1):51-54.

32. Gladys S, Van MB, Lambrechts P, Vanherle G. Microleakage of adhesive restorative materials. American Journal of Dentistry 2001;14(3):170-176.

33. Yazici AR, Ozgunaltay G, Dayangac B. The effect of different types of flowable restorative resins on microleakage of Class v cavities. Oper Dent 2003 Nov-Dec;28(6):773-778.

34. Jain P. Ormocer-biocompatible, replacement for amalgam, composite and compomers. Journal of Conservative Dentistry 2001;4(2):79-83.

35. Welbury RR, Shaw AJ, Murray JJ, Gordon PH, McCabe JF. Clinical evaluation of paired compomer and glass ionomer restorations in primary molars: Final results after 42 months. Br Dent J 2000;189(2):93-97.

36. Sikri V, Singh H. A comparative evaluation of light cure composites, light cure glass ionomers and compomers for restoration of cervical abrasion erosion lesions-An in vivo and in vitro study. Journal of Conservative Dentistry 2002;5(1):2231.

37. Yap AU, Mok BY. Surface finish of a new hybrid aesthetic restorative material. Oper Dent 2002 Mar-Apr; 27(2):161-166. 